\title{
Opportunities and Challenges for Management Accounting in the Era of Big Data
}

\author{
Li Penglin ${ }^{1, a}$, Zhao Jiali ${ }^{2, b,{ }^{*}}$ \\ ${ }^{1}$ School of Management, Xi'an University of Science and Technology, Xian, Shaanxi, China \\ ${ }^{2}$ School of Management, Xi'an University of Science and Technology, Xian, Shaanxi, China \\ bemail 920859810@qq.com \\ ${ }^{*}$ Corresponding author Zhao Jiali
}

Keywords: Big data, Management accounting, Opportunities, Challenges.

\begin{abstract}
In recent years, the rapid development of the Internet and information technology has created a new era of information, and spurred the advent of the era of big data. Tremendous changes have also taken place in enterprises in terms of data collection, processing, and use, which has made management accounting increasingly important in enterprises. In the era of big data, enterprises' management accounting faces new challenges and opportunities. The effective use of such big data by management accounting can provide enterprises with more accurate basis for business and decision-making, creating great opportunities for their development. This puts forward higher requirements as well as great challenges for enterprises' management accounting. This paper, based on the era of big data as the background, expounds the new opportunities and challenges that management accounting faces, and proposes corresponding countermeasures so as to effectively combine management accounting with big data and to promote the development of management accounting so that companies can keep pace with the development of the era of big data and create greater economic value.
\end{abstract}

\section{Introduction}

In the era of big data, the rapid development of information technology and the Internet of Things has led to a huge amount of data coming in. In the process of collating and analyzing these data and unearthing their potential value, enterprises can obtain more valuable new information from them in order to achieve the improvement of corporate interests, so the future development of enterprises cannot be separated from the use of big data. The huge amount of data brings great difficulties to data collection, sorting, and analysis. Management accounting, as the main processor and analyst of enterprise information, will also face greater challenges. However, big data is a double-edged sword. It brings challenges and also rare development opportunities for the development of management accounting. Therefore, management accounting needs to take effective countermeasures to meet challenges, seize opportunities, and fully play big data's role. Therefore, the use of big data has brought opportunities and challenges to enterprises and provided them with more valuable reference information, and also promoted the development of management accounting.

\section{Opportunities for management accounting in the era of big data}

\subsection{Enhancing enterprises' forecasting capabilities}

In the era of big data, mobile Internet has become the focus of the development of the Internet. According to data released by China Internet Network Information Center, as of December 2017, the number of Internet users in China has reached 772 million, and the penetration rate has reached $55.8 \%, 4.1 \%$ higher than world average level, and 9.1\% higher than Asian average level. Among them, mobile Internet users accounted for $97.5 \%$. The percentage of Internet users using mobile devices to access the Internet is way higher than that of other network devices, which serves as a sign that mobile phones are no longer the tools traditionally used to receive calls and send text 
messages, but become a medium for network information transmission. Now many enterprises in China have opened official account on Weibo and WeChat platforms where enterprises can publish their own new products, communicate with potential users, obtain new information, and improve their products and services, and users can also post how they feel. These tools make information transfer more conveniently. Enterprises can make full use of the data brought by these tools to obtain information timely. Through the forecasting techniques and methods of management accounting, they can sort and classify information, and then perform quantitative analysis and make rational judgments. They keep abreast of the latest trends of the entire market, understand the latest developments of the opponents, analyze the possible trends of the market, and quickly and rationally plan their development strategies so as to obtain market advantages.

\subsection{Strengthening enterprises' decision-making capabilities}

In the information age, consumers carry on transactions through the Internet, and their trading behaviors will leave traces on the Internet. It is easy for enterprises to obtain their online purchase records under the support of big data technology. Even if consumers do not purchase, browsing traces are still recorded on the Internet. Enterprises can analyze these data and can effectively tap their potential value. Just like Taobao that people often use in China will analyze their consumers' preferences based on their browsing traces. When consumers open the App's home page again, it will automatically recommend the products they searched for, precisely because of the fine-grained analysis of consumers' behaviors, enabling it to occupy more than half of online shopping market. Therefore, enterprises can recommend possible product information based on the consumer's behavioral preferences and promote the sales of their own products. At the same time, the management accounting personnel can perform more effective search and analysis on this complex information in the context of big data, which thus enables enterprises to timely adjust production and management strategies, and enhance their core competitiveness and the scientific and accurate decision-making.

\subsection{Improving the efficiency of enterprise operation and management}

Management accounting can collect a large amount of data and conduct a thorough investigation of the market. Through the processing of data, it can have an overall grasp of the operating costs of the enterprise, and thus help it reduce unnecessary investment and production costs, and determine the optimal production and sales scale, and formulate appropriate management plans to help reduce costs. The use of big data makes it easier for management accounting to improve work efficiency while simplifying work. The results of various data analysis are more easily found in the context of big data. Effective integration of enterprises' production with information technology can, under the principle of reducing cost, reasonably adjust and optimize their capital structure, and quickly improve their production technology and processes, thereby furthering control accurately the cost input, improving the efficiency of operation and management, and ensuring their maximum benefit.

\subsection{Improving the scientificity of corporate performance evaluation}

The performance evaluation of an enterprise is an important part of its business activities, and it is also a difficult issue in management accounting. It is difficult to collect all evaluation data related to performance. The advent of the era of big data will avoid the unfairness of performance evaluation on employees and departments caused by insufficient information. After the data are collected and analyzed by management accounting, the enterprise can not only evaluate the performance of internal employees and its overall benefits, but also can know the development performance of its competitors and even the entire industry, and then can carry on more scientific and reasonable evaluation on its performance. Under the big data environment, employees and departments can be managed according to advanced scientific methods, such as the perception of social media, the application of Web transaction systems and so on, which can affect the working status of employees. At the same time, enterprises can also make full use of big data to tap ways of incentive in many aspects to establish scientific and fair incentive policies and reward and punishment rules, then increasing their loyalty and stimulating their potential. 


\section{Challenges that management accounting faces in the era of big data}

\subsection{Insufficient understanding of the application of big data in management accounting}

Big data, an emerging product, has risen in recent years with the booming development of network and computer. However, many enterprises do not recognize its importance in their operation, especially many small and medium-sized enterprises which consider that big data are exclusive to some large enterprises and they smaller ones are short of enough financial resources, manpower, and energy for big data applications. But the truth is that management accounting of all enterprises requires a large amount of data support to provide scientific and effective basis for decision-making. Therefore, the importance of big data to management accounting is obvious. Yet, the lack of attention from enterprises and the imperfect use of big data can hinder management accounting and their development.

\subsection{Insufficient information storage space}

The huge amount of data is the biggest feature of the big data era. The era of big data requires enterprises to collect all relevant data accurately and timely, while also emphasizes the continuity, adequacy and comprehensiveness of information. Therefore, this requires a large enough storage space to store information. According to statistics, Taobao stores up to 50TB information every day, and Baidu processes 1PB data per day. Every day, various social networks and mobile networks generate huge amounts of data, so ample space for these data to be stored is needed. However, existing storage media cannot meet the requirements for processing and storing TB-level data sets.

\subsection{Information insecurity}

If management accounting wants to use big data to effectively guide the enterprise's production and management, the key is the accuracy and security of the data. The information collected by the enterprise includes the secret information of individuals and organizations. For example, chat and map applications on our mobile phones are required to obtain various authorizations before they access to users' information. Once the information is obtained by people lawlessly, it not only brings risks to users, but also the enterprise who designed these Apps will face moral criticism, financial and even legal penalties. In reality, there are still many Trojan horses and hacking viruses which also pose a threat to the information security of enterprises. Once a series of sensitive data in an enterprise's data systems such as corporate reports and customer data is leaked to peer companies, the loss can be huge. Therefore, if an enterprise's information leaks, it will cause serious damage to its development, and even lead to bankruptcy. However, nowadays the security of management accounting information is still not fully guaranteed.

\subsection{Shortage in management accounting personnel}

At present, China's recognition of management accounting is mainly based on U.S.A. IMA. In cooperate operation, information processed by big data cannot be used directly by the enterprise, so professional management accounting personnel are required to carry out in-depth excavation and refinement of information to be used by managers to make decisions. However, at present, not only China, there are serious shortages in management accounting personnel in various countries around the world. Before Liu Junyong, a well-known Professor at Central University of Finance and Economics, believed that management accounting personnel in the next decade will be China's "blue ocean" with a shortage of 3 million. This shows that China's professional management accounting personnel are extremely scarce. In the era of big data, personnel shortages are the major problem to be resolved first in order to promote the rapid development of management accounting. Management accounting personnel in the era of big data is a new type of management accountant that, based on professional knowledge of management accounting, can analyze data information through information analysis tools and provide reasonable decisions. The lack of professional data analysts has made the development of management accounting and innovation of information technology face certain difficulties. Therefore, whether timely training on management accounting 
talents who possess the knowledge and skills needed for such analysis can be achieved or not is critical to the development of the enterprise.

\section{Countermeasures of management accounting in the big data era}

\subsection{Strengthening the awareness of applying management accounting in big data}

The development of big data, a trend of the time, brings opportunities for the development of enterprises and enterprises must seize them. To grasp the opportunity of big data timely and meet its challenges effectively, the first priority is to raise awareness of the role of management accounting in the era of big data. First of all, the departments concerned should take the initiative to provide necessary policy and infrastructure support for management accounting in making full use of the resources of big data. Editing and publishing accounting publications, monographs, and materials relating to big data, integrating big data related knowledge into management accounting learning, and promoting and strengthening management accounting professional education, make the impact of big data on management accounting widely known to massive accounting practitioners and learners. Second, China's scientific research institutions can research and summarize management accounting theory that suits China's national conditions, build China's own management accounting theory system, advancing with the times, and combine management accounting with big data to provide a theoretical basis for the application in enterprises. Finally, as an enterprise, it is more important to recognize big data's huge driving force on management accounting, and pay attention to its development, so that managers and employees can actively learn relevant knowledge and consciously apply big data to management accounting practice, improve the level of application of management accounting in practice, promote the development of management accounting, boost the economic efficiency of enterprises, and lay a good foundation for the enterprise's subsequent development.

\subsection{Effective use of cloud computing applications}

The era of big data requires that information storage tools must have a large enough capacity. Only a database that can accommodate terabytes of data or higher is built, the storage of information collected and quick analysis are available. The resulting cloud computing is a response to this. In the process of analyzing and collating data, cloud computing processing technology not only enhances the effective analysis of data information, but also reduces the time cost. At the same time, cloud computing can also support the analysis demand on zettabyte-level massive structured, semi-structured, and unstructured information. Enterprises can use cloud technology to store information on the cloud platform. This does not occupy an enterprise's own storage space. The application programs that it needs are also running at high speed in the Internet's large-scale server cluster, which not only greatly increases the efficiency of enterprise storage and analysis of information, but also enables the deep mining of data, making their value fully visible. To a certain extent, building a cloud-based accounting information system is currently the most direct and effective method to solve big data storage and analysis problems.

\subsection{Completing information security protection system}

The era of big data brings convenience to the development of the enterprise and also brings security risks. The security of information management systems is the basis for an enterprise to gain an advantage in an increasingly competitive market environment. In order to better realize the protection of big data information of enterprises, national government departments and enterprises need to assume their respective responsibilities. First of all, the country needs to establish a corresponding legal mechanism for problems concerning information leakage in the era of big data to ensure the security of information of enterprises and the general public. At the same time, it is necessary to increase enforcement efforts and impose severe penalties on organizations and individuals that maliciously steal information from others, and also on those who divulge information. Second, when companies select cloud computing service companies, they need to 
conduct comprehensive research and comparison, and select more stable and safer service providers. At the same time, it is also necessary to strengthen the supervision of cooperative companies and formulate a sound confidential system, backup management and risk response plan. In addition, cloud computing should be equipped with data isolation function to prevent unauthorized access. Different administrators should be set up with their own rights to prevent them from arbitrarily altering, destroying, stealing, and forging data so as to protect customers' information security.

\subsection{Focusing on training management accounting personnel}

Compared with financial accounting, management accounting has higher requirements on talents. Management accountants not only need to master the theories and methods of traditional accounting, but also need to fully understand the operation modes of various types of businesses and understand the details of related businesses. It can be said that enhancing management accounting personnel is the core of management accounting development in the era of big data. Therefore, in order to promote the development of management accounting in this era, the key is to strengthen the training of management accounting personnel. First of all, the government can increase the proportion of examination questions about big data and management accounting by reforming the contents of Accounting Title Examinations, and introduce corresponding training policies and mechanisms in personnel training. Secondly, colleges and universities can set up specialized management accounting majors, formulate talent training plans that emphasize the combination of theory and practice, and customize a complete management accounting training system. Finally, enterprises can call on financial personnel to actively participate in their decision-making and operation, and conduct regular training on them, like organizing them to learn the application of management accounting, and sending accounting personnel to exchange and learn from domestic and foreign professionals, so that they can continue to optimize their knowledge reserves, and strive to become a good management accounting talent and become a management accountant who is good at processing data, and use their own knowledge reserves to contribute to the enterprise's operation and development.

\section{Summary}

The era of big data makes the collection of management accounting data more convenient and comprehensive and makes the data of enterprises increasingly rich and networked. It provides a basis for management accounting to have reliable reference information and further refine valuable information, thus promoting its development in the process of management decision-making. The era of big data brings opportunities and also challenges for enterprises. In this era where the competition among enterprises is becoming increasingly fierce, when enterprises actively respond to the challenges, they should grasp the practical application of management accounting and big data, win new development opportunities, and then maintain their economic benefits. Enterprises can rely on advanced management concepts and technologies to promote the work of management accounting. Based on the full awareness that the use of big data will bring tremendous benefits to enterprises, they should face up to the problems that arise in the process, and improve the use of big data in management accounting. They also should attach importance to the innovation and safety of technology, continuously improve the overall quality and ability of management accounting, and complete the training of management accounting personnel, and thereby promote the overall level of corporate accounting, so that enterprises can keep pace with the process of the big data era, create greater economic value, and ultimately maximize their economic benefits.

\section{References}

[1] Liang Yong, Research on Accounting Informationization Transformation Based on Big Data and Cloud Computing, China Management Informatization, vol.23, pp. 20-22, 2013. 
[2] Wang Yifan, The Challenge for Management Accounting from the Perspective of Big Data, Chinese and Foreign Entrepreneurs, vol.14, pp. 43-44, 2014.

[3] Su Fangyu, Challenges for Management Accounting and Countermeasures in the Era of Big Data, Times Finance, vol.15, pp. 12, 2015.

[4] Zhang Yonghong, Thoughts on the Development of Management Accounting in the Big Data Era, China Chief Financial Officer, vol.6, pp. 34-35, 2015.

[5] Wu Lifang, Challenges for Management Accounting and Countermeasures in the Big Data Era, China Business Update, vol.24, pp. 151-152, 2016.

[6] Yao Wenchao, Challenge for Management Accounting of Traditional Manufacturing Enterprises in the Era of Big Data, Chinese and Foreign Entrepreneurs, vol.17, pp. 70-71, 2016.

[7] Yu Qi, Wang Di, Challenges for Enterprise Management Accounting and Countermeasures in the Era of Big Data, China High Technology Enterprises, vol.12, pp. 167-168, 2016.

[8] Li Han, Opportunities and Challenges for Management Accounting in the Era of Big Data, Modern Business, vol.21, pp. 148-149, 2017.

[9] Zeng Dingjun, Opportunities and Challenges for Management Accounting in the Era of Big Data, Market Modernization, vol.16, pp. 152-153, 2017.

[10]Zhu Chunyun, Applied Research on Management Accounting in Enterprises, Accounting Learning, vol.12, pp. 102-103, 2017. 